\title{
Development Financial Institutions: Impact Investing Practices in Scandinavian Context
}

\author{
Oxana Wieland
}

Business Department, University of Minnesota, USA

Copyright $\bigcirc 2016$ by authors, all rights reserved. Authors agree that this article remains permanently open access under the terms of the Creative Commons Attribution License 4.0 international License.

\begin{abstract}
Socially responsible Investing (Impact Investing, Sustainable, Ethical, Green investing) that offers pragmatic and social outcome deliveries have become rapidly adopted financial innovations in Scandinavian countries. Impact investing is considered to be one form of socially a responsible investment strategy in the global arena which considers both financial return and social impact (best intentions, outcomes). This research will evaluate Social Impact Investing (SII) practices with particular attention to the private equity companies NORFUND, which is owned by the Norwegian Ministry of Foreign Affairs. Each of three independent case studies is examined in a comparative analysis based on the following criteria: 1) Economic conditions, 2) investment environment, 3) ease of doing business, 4) performance of the Norwegian Development Cooperation, 5) relevance, 6) constraints and 7) opportunities. Results of the analysis show that success or failure of a given venture is tightly coupled to the political environment and existing infrastructure, both financial and real (roads, power distribution etc...). Suggested improvements based on the analysis include a focus on improving several existing programs.
\end{abstract}

Keywords Impact Investing, NORFUND, Development Finance Institution, Africa, Sri Lanka, Match Making Programs

\section{Introduction}

NORFUND's mission has been identified as a providing help to developing countries in order to fight poverty through supporting economic growth. This research paper will use this type of example of practical experience as a case study of socially responsible innovative financial instruments in order to understand the complexity and resulting challenges of this potential market instrument. This research indicates that the regulatory regime governing Scandinavian markets and social investment institutions is worth analyzing in order to disseminate best practices of the implementation of SII as a financial innovation. In particular, existing institutions, such as Private Equity Companies Funds, need to be considered in order to understand the factors that will determine defined targets of social investing practices.

NORFUND and similar organizations are known as Development Finance Institutions (DFI). DFI's exist in many countries throughout the world. In some cases, these institutions collaborate through associations. In the case of European DFI's, one well known association is the Association of European Development Finance Institutions (EDFI) which consists of fifteen unique DFI's. The stated goal of these associations is to increase information flow and cooperation between members and other potentially vested parties. Projects taken on by DFI's generally target developing countries where various forms of investment are projected to have a positive impact on sustainable business growth, leading to reduced poverty.

The research examines several case studies regarding the investment of DFI funds in developing countries to measure the impact of those investments. An examination of the standards adopted by the DFI's will also be examined. Reports from independent assessments will be reviewed to add to the understanding of the measurements used to determine positive outcomes.

Development Finance Institutions (DFIs) are banks, the majority ownership of which is usually national governments. DFIs target high risk projects which are unlikely to be considered by commercial banks. There are two types of DFIs: Bilateral and multilateral. Bilateral DFIs provide a mechanism for the investing country to engage in foreign development in the interest of the investing country while multilateral DFIs (also known as IFIs or International Financial Institutions) attempt to create close ties between governments. Multilateral IFIs generally have greater funding resources from which to draw. DFIs source their capital from national and international funds, and sometimes in the form of government guarantees. Development Finance Institutions face a myriad of challenges in pursuing their goal of creating sustainable 
business in developing countries. In the broadest terms, 'sustainable business' refers to ' best practices in business, governance, and environmental standards'[refer to development financial institutions defined]. European countries have a relatively long and active history of investing in developing countries, in particular, in Africa. NORFUND, a member of the Association of European Development Finance Institutions is a good example as it has a well-known history as a DFI with a very active portfolio of projects. (http://www.edfi.be/) NORFUND was established by a Norwegian parliamentary act in 1997, and therefore has a fair amount of history, though not as much as some others, most notably the CDC founded in $1948^{1}$. In each of the case study reports, it is stated that NORFUND's ultimate goal is to eliminate poverty. This is the key underlying theme throughout the case study reports.

Of note is that the case studies approach a 'case' in terms of investment in a country, drawing on a variety of efforts within the given countries borders. Investments are made using a number of investment tools spanning a range from micro-finance in support of women with small businesses all the way to infrastructure development firms which involve themselves with building dams or developing communications businesses.

Each country is unique in that the historical background, whether cultural, political, or geopolitical provides challenges that make investing in the country challenging. Recent conflicts, internal political unrest, resource availability and many other factors impact what and how sustainable investing can be implemented. As a result, the parties involved in a given project and how capital is raised along with the mix of public (DFI) and private investment varies. Most of the investments are considered high-risk and therefor unlikely to be initiated by private investment alone. The strategy employed is to provide substantial financing and underwriting from public sources (DFIs) in order to attract initial private investment. One of the measurements of success then is that private investment, both within the country and from without grows and continues to grow mitigating the need for DFI backing, (especially in the form of aid/grants), as the primary sources of funding projects.

The goal of DFIs is to invest in such a way that there is of course an ROI for both the public/private investors as well as sustainable businesses which improves the lives of those in the country that is being invested in. (Musasike, Stilwell, Makhura, Jackson, \& Kirsten, 2004) Specific targets such as eliminating poverty and improving the lives of women are hard to measure in the short term at the scale of an entire country. As such, the measurements of impact are couched in terms of providing a long lasting and growing opportunity for those populations in the targeted country. In this research, the research will examine three countries in which Norway has invested through

1 http://www.cdcgroup.com/Who-we-are/Key-Facts/
NORAD/NORFUND: Sri Lanka, South Africa, and Uganda.

To adjust to the many dynamics of a target country, measurement of success or lack thereof is needed. Which programs work, and which do not seem to? Do given efforts contribute to the overall mission of the DFI and its SII goals? This research suggests that better planning for the measurement of success is possible and should be implemented. Additionally, risk management, financial and legal competencies and ensuring compliance are areas which research shows needs improvement. This research will examine basic components of independent cased studies targeting South Africa, Sri Lanka, and Uganda. The basic components are:

1. Economic Conditions

2. Investment Environment

3. Ease of Doing Business

4. Norwegian development Cooperation

5. Relevance (Impact/Efficiency/Sustainability)

6. Constraints

7. Opportunities

\section{Literature Review}

\section{Planning for and Measuring Success}

Success and failure of projects undertaken and underwritten by DFIs such as NORFUND have provided valuable lessons for when, how, and where investments work to achieve the goals of DFIs. It is clear that the timing of engagement in financial investment, the types of financing as well as the location of investment relative to resources both hard and soft is important. Determining answers to those questions is an area of learning that is both ongoing as well as dynamic. In order to make the case study relevant, however, measurements of the impacts must be planned for ahead of time.

"Many governments, institutions, and project managers are reluctant to carry out impact valuations because they are deemed to be expensive, time consuming, and technically complex, and because the findings can be politically sensitive, particularly if they are negative. Many evaluations have also been criticized because the results come too late, do not answer the right questions, or were not carried out with sufficient analytical rigor. A further constraint is often the limited availability and quality of data. Yet with proper and early planning, the support of policymakers, and a relatively small investment compared with overall project cost, a rigorous evaluation can be very powerful in assessing the appropriateness and effectiveness of programs. Evaluating impact is particularly critical in developing countries where resources are scarce and every dollar spent should aim to maximize its impact on poverty reduction. If programs are poorly designed, do not reach their intended beneficiaries, or are wasteful, with the right information they can be redesigned, improved, or 
eliminated if deemed necessary. The knowledge gained from impact evaluation studies will also provide critical input to the appropriate design of future programs and projects." (Baker, 2000)

The case study reports are consistently organized and contain or refer to a fair amount of empirical evidence. They however do not contain counterfactual evidence from which to draw comparison which would provide more compelling and complete arguments for the key finding in each section of the report as recommended by Kapoor. (Kapoor, 2002) The lack of substantial evidence for either a before-after or with-without counterfactual methodology applied. (Khandker, Koolwal, \& Samad, 2010)

In order to analyze the case studies using known best practices, the Handbook on Impact Evaluation: Quantitative Methods and Practices was found to be informative. The handbook suggests that:

"The main challenge across different types of impact evaluation is to find a good counterfactual-namely, the situation a participating subject would have experienced had he or she not been exposed to the program.". (Khandker et al., 2010)

Counterfactuals provide the baseline, or control, for impact studies. However, a true counterfactual is also very hard to obtain as the act of adding a counterfactual to an impact study. The inclusion of the counterfactual implies observation and therefor knowledge of the program by the counterfactual. This is basically a loose application of the Schrödinger's Cat problem where the outcome is influence by the observation. Therefore, the suggested solution is to identify and select units (ex. Families) which are similar in as many ways as possible. Not an easy task, but if done with care, can provide a solid counterfactual. Designing an impact study to include counterfactuals consists of using good statistical study design principles. When possible, it is clear that impact studies benefit greatly from empirical study based on statistical methods and that the methods have been developed and applied.

But what about cases where there is little or questionable empirical data available? Baker (2000) supports the idea of rigorous design using statistical methods to gain understanding of impacts. However, there is an acknowledgment that there are situations in which due to various limitations such as time constraints that that achieving this rigor is difficult.

"To ensure methodological rigor, an impact evaluation must estimate the counterfactual, that is, what would have happened had the project never taken place or what otherwise would have been true." (Baker, 2000)

"This technique is, however, dependent on having the right data because it relies on oversampling program beneficiaries during the fielding of a larger survey and then "matching" them to a comparison group selected from the larger core sample of the overall effort, often a national household survey." (Baker, 2000) Baker also points out that there is important information to be gained by at least combining Qualitative Methods with quantitative methods. Qualitative methods are used to gain understanding the perception of process, behaviors, and conditions. It is pointed out that qualitative methods then are used in conjunction with other techniques and can itself then be quantified. The advantage is that qualitative techniques:

"...can be carried out quickly using rapid techniques, and can greatly enhance the findings of an impact evaluation through providing a better understanding of stake holders perceptions and priorities and the conditions and processes that may have affected program impact." (Baker, 2000)

The drawback is the subjectivity of such methods is subjectivity and the impossibility of deriving a counterfactual and thus causality of the project impacts. Thus an integrated approach of using both methods is beneficial to gaining understanding of impacts: Consistency, multilevel analysis, and opportunities for feedback are all advantages to an integrated approach.

Other methods such as evaluation of adjustment policies and theory based evaluations have shortcomings in that inherent assumptions are hard to identify, the lack of good tools and the knowledge to use them may present evaluators with problems accurately measuring, the underlying concept of measurements may be too broad, and tests may be subject to interpretation.

Considering the many influences that might determine the perceived benefits of implementing an impact study and how it might be implemented is depicted in Figure 1.

\section{Environmental, Social, and Governance Data}

Providing information regarding Environmental, Social and Governance (ESG) policies and data of potential investee projects to potential investors, whether public or private, is becoming a norm. It has been argued that there is a compelling reason for ESG disclosure be mandated. In a Global Corporate Governance Forum Publication (Lydenberg, 2014) for example, the evidence presented argues that a worldwide mandate of such disclosure would "acknowledge the essential role these data can play in bringing about the alignment of market forces with society's interests." ESG reporting is being driven by a number of forces: 1) Lack of trust in finance, 2) materiality and long-term investor interest, 3) demographics, 4) social justice and 5) natural resources. Whether or not one agrees or dis-agrees with the effectiveness of ESG and whether or not it should be mandated, evidence shows the trend for applying it as a standard is growing. 


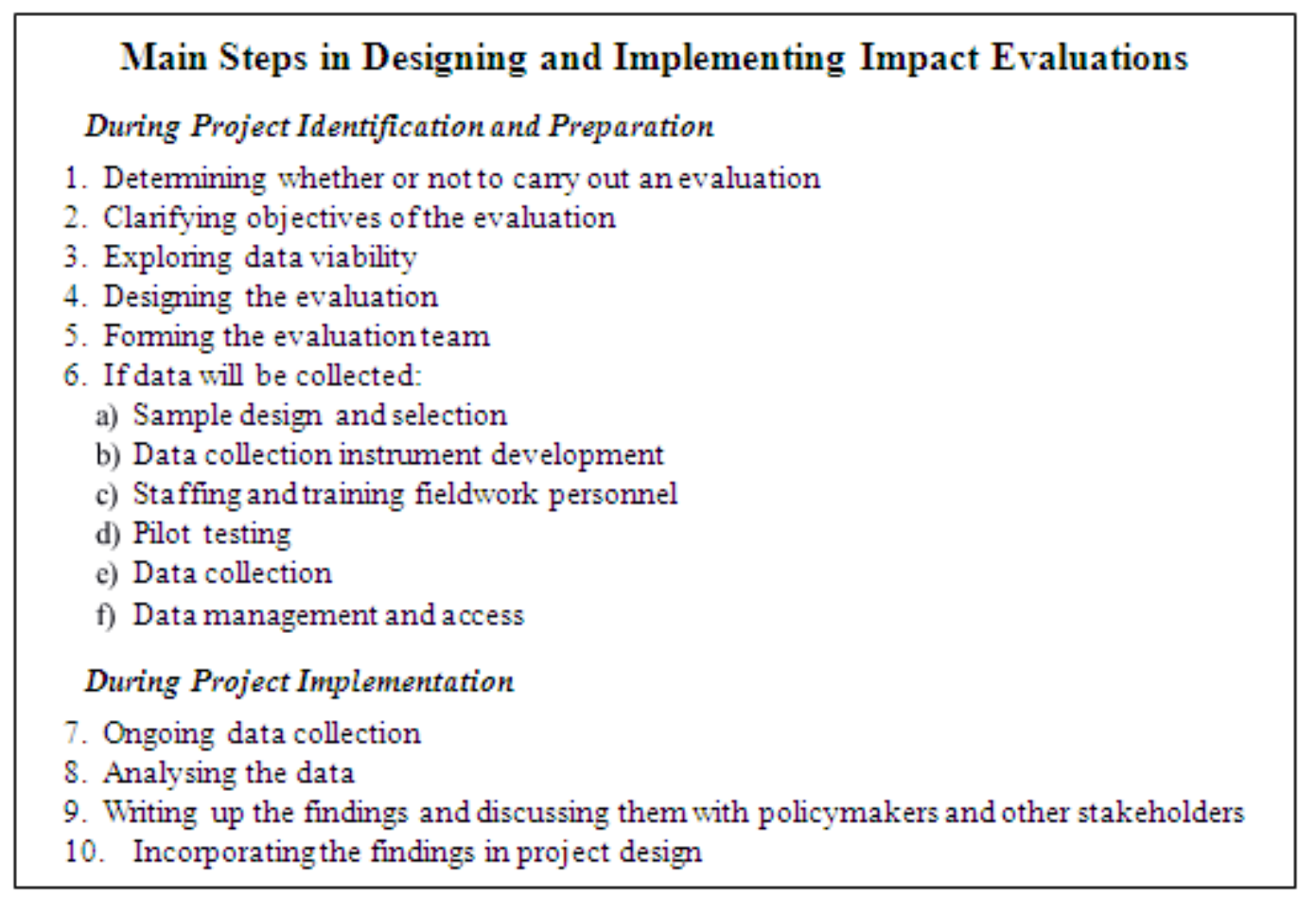

Figure 1. (Source: Baker, pg 17, Box 2.1)

\section{Comparing DFIs}

In 2011 Schmidt and Winkler examined DFI's in Europe using four case studies centered around the CDC, NORFUND, the DEG, and the FMO. The work focused on the question of methods used to assess a projects relevance and DFI funding priorities. (Schmidt \& Winkler, 2011) In that work, the case studies showed differences between European DFI's, but did not examine individual projects within each DFI. Of note in that study is that importance was laid on both transparency and governance as well as project evaluation.

\section{Labor and Transformation}

Micro and macro level impacts of DFI projects are not easy to quantify as pointed out by Jouanjen and te Velde. (Jouanjean \& te Velde, 2013) Both direct and indirect employment impacts are measured using multiple methods and within varying contexts. No standard model appears to have been developed as of yet. The paper points out that DFIs put more emphasis on direct employment, leaving out indirect labor market impacts at a macro level. And yet their paper suggests that DFIs do in fact have an impact on labor productivity and as a result on labor level.

\section{The Methodology and Analysis Approach}

This paper analyzes three case studies which examine the performance of DFI projects in the countries of South Africa, Sri Lanka and Uganda undertaken by NORFUND. The case studies were executed by Devfin Advisors between 2009 and 2010.

\section{Objectives}

This paper uses as a guide the steps laid out in Figure 1 of the literature review where appropriate as a guide for the analysis of the case studies examined. The initial design then is as follows:

- To identify the most relevant methods for the external evaluation of the Development Finance investing.

- To investigate the Impact Investing practices in Scandinavian context, using the example of the Norwegian Development Fund (NORFUND)

- To understand the role of NORFUND as an instrument of Norwegian development assistance policy through the case study documentation of the outcomes of its development activities.

- To outline the best practices for the future programming of development financing for sustainable private sector development in least developing countries.

Three primary case studies are examined along with other documents related both specifically and generally to those case studies. These case studies are related to efforts in which NORFUND was one of the primary investment funds, and in all cases, NORFUND sponsored the studies. The case studies examined are part of a set of four case studies commissioned. The case studies of countries (projects) included are Uganda, Sri Lanka, and South Africa. (The case study for Bangladesh was not examined for this paper.) The methodologies used for each report are similar. 
These three characteristics provide a basis for examining the results of projects engaged in by a well-known DFI.

Additionally, other documents which contribute to this paper examine more broadly the varying expectations of the roles which DFIs play in reducing/eliminating poverty and helping to build sustainable businesses in developing countries.

The three case studies were examined relative to the following criteria:

1. Economic Conditions

2. Investment Environment

3. Ease of Doing Business

4. Norwegian development Cooperation

5. Relevance (Impact/Efficiency/Sustainability)

6. Constraints

7. Opportunities

\section{The Findings}

\section{South Africa}

\section{Economic Conditions}

South Africa as of 2010 makes up 38 percent of the Sub-Saharan GDP, has the 17th largest stock exchange in the world, and modern infrastructure along with well-developed financial, legal, communication and transport sectors. With a population of 47 million, a GDP of $\$ 467$ Billion (2007 est.) imports/exports of approximately $\$ 148$ Billion and a 5\% growth rate, it is considered to be a middle income emerging market. Along with these very positive numbers are some which show challenges which are faced however. Unemployment is upwards of $24 \%$, Infant mortality is above $59 \%$, average life expectancy is only 50.5 years. Additionally, there is a large disparity in income and consumption between ethnic groups with white people owning the better percentage of businesses and having business opportunities. (Devfin Advisors, 2010)

Post-apartheid South Africa is still considered to be one of the most unequal societies in the world. Income and asset equality are still considered to be severe. Of the total consumption of the population, only $10 \%$ of consumption is by $53 \%$ of the population with $2.8 \%$ being consumed by the poorest 20\%. Between 1995 and 2000 those living in poverty increased from 28 to 33 percent. HIV/AIDS and adult mortality have also been issues with the latter being three times higher than similar middle income countries with regard to income per capita.

In the area of competitiveness, South Africa is by far rated 45 out of 133 countries. A relatively stable economy, developed financial markets, institutional quality, IP protections, private institutions accountability, innovation and market efficiency all contribute to this ranking. Conversely, labour market inefficiencies, inflexible wage and labour laws, skills deficiencies, dated infrastructure, crime and poor health services are challenges which still need to be addressed in order to become more competitive.

\section{Investment Environment}

Foreign Direct Investment (FDI) has grown substantially between 2005 and 2010 as shown in table 1 due to sound economic policy and entrepreneurial strength. In 2007 it was ranked $18^{\text {th }}$ out of 25 of the most attractive FDI destinations in the world.

Table 1. South Africa: Foreign Direct Investments: inward \& outward flows (USD millions)

\begin{tabular}{|c|c|c|c|c|c|}
\hline \multicolumn{2}{|c|}{$1990-2000$} & \multicolumn{4}{|c|}{} \\
\hline & (annual Average) & \multicolumn{3}{|c|}{} \\
\hline Inward & 854 & 6,644 & $-527^{*}$ & 5,687 & 9,009 \\
\hline Outward+ & 606 & 930 & 6,067 & 2,962 & $-3,533$ \\
\hline
\end{tabular}

Source: http://www.unctad.org/sections/dite_dir/docs/wir03_fs.za.en.pdf

\section{Ease of Doing Business}

As an upper middle income country, South Africa is ranked in the Doing Business Report as 34 out of 183 economies in term of Ease of Doing Business, better than any other African country as shown in table 2 .

Table 2. Doing Business in South Africa

\begin{tabular}{|c|c|c|c|}
\hline Ease of... & $\begin{array}{c}\text { Doing Business } \\
\text { 2010 report rank }\end{array}$ & $\begin{array}{c}\text { Doing Business } \\
\text { 2009 report rank }\end{array}$ & $\begin{array}{c}\text { Doing Business } \\
\text { 2008 report } \\
\text { rank }\end{array}$ \\
\hline Doing Business & 34 & 32 & 35 \\
\hline Starting a Business & 67 & 47 & 57 \\
\hline $\begin{array}{c}\text { Dealing with } \\
\text { Construction Permits }\end{array}$ & 52 & 48 & 47 \\
\hline Employing Workers & 102 & 102 & 96 \\
\hline Registering Property & 90 & 87 & 78 \\
\hline Getting Credit & 2 & 2 & 2 \\
\hline Protecting Investors & 10 & 9 & 9 \\
\hline Paying Taxes & 23 & 23 & 65 \\
\hline $\begin{array}{c}\text { Trading Across } \\
\text { Borders }\end{array}$ & 148 & 147 & 137 \\
\hline Enforcing Contracts & 85 & 82 & 83 \\
\hline
\end{tabular}

(Source: Devfin Advisors, 2010b) (pg, 13)

\section{Norwegian Development Cooperation}

Norway has history with South Africa dating back to the 1840 's. As of the establishment of the United Nations in the 1940 's, Norway has had specific foreign policy positions toward Africa and was active in South African regime change in apartheid South Africa. Later, in the 1950's Norway attempted a policy of 'constructive engagement' in order to apply influence and subsequently engaged in development assistance to the liberation in the early 1970's. Ongoing debate continues between concerned parties regarding the role of Private Sector Development leading unfocused development efforts. Norway continued support for the liberation movement until 1994 when elections brought freedom to South Africa. 
Commercial ties between South Africa and Norway as of 2010 were not significant. Less than $1 \%$ of South African exports enter Norway. Much of this is due to environmental standards required for imports to Norway, though until 2002 tariffs also had an impact. Overall, only $0.5 \%$ of Norway's import/exports are with South Africa although this took a dramatic jump in 2008 as shown in figure 1. As mentioned previously however, Norway does very little business with South Africa when taken in context. Only $0.3 \%$ and $0.2 \%$ of South Africa's imports and exports respectively are comprised of business with Norway. Imports/exports notwithstanding, South Africa is seen as a gateway to sub-Saharan Africa and there is interest being shown by Norwegian companies in everything from joint ventures to exploration of small, micro and medium enterprises (SMMEs).

Norway's development cooperation with South Africa targets several key development objectives, those being:

$\begin{aligned} \text { i. } & \text { Democracy/Human Rights/Peace and Security } \\ \text { ii. } & \text { Higher Education and Research } \\ \text { iii. } & \text { Environment and Natural Resources } \\ \text { iv. } & \text { Energy }\end{aligned}$

South Africa is unique in its relationship with Norway in that it has transitioned from a country in need of support to one of equal partner. As of 2010 aid to South Africa is seen as coming to an end with collaboration on global issues such as cooperation taking over as key aspects of the relationship.

Private Sector Development in South Africa:

Norwegian PSD projects and programmes in South Africa since 1999

\begin{tabular}{|c|c|c|c|}
\hline Programme & Year & NOK Mill & Description \\
\hline \multicolumn{4}{|c|}{ Norad programmes } \\
\hline $\begin{array}{l}\text { Matchmaking } \\
\text { programme }\end{array}$ & 1997-2009 & $\begin{array}{c}3 \text { per } \\
\text { annum }\end{array}$ & $\begin{array}{l}\text { Implemented under } \\
\text { contract with Norad by } \\
\text { Innovation Norway, } \\
\text { Johannesburg }\end{array}$ \\
\hline $\begin{array}{c}\text { Application-based } \\
\text { support }\end{array}$ & Since $1970 \mathrm{~s}$ & $\begin{array}{l}5 \text { per } \\
\text { annum }\end{array}$ & $\begin{array}{c}\text { About } 200 \text { projects over } \\
1999-2009\end{array}$ \\
\hline Institutional support & $1999-2003$ & 4.6 & $\begin{array}{c}\text { Probably five } \\
\text { institutional }\end{array}$ \\
\hline Norad's soft loan & $1998-2000$ & 40 & Two loans \\
\hline \multirow[t]{4}{*}{ NORFUND } & 1999-2009 & 237 & $\begin{array}{l}\text { Disbursements made } \\
\text { through }\end{array}$ \\
\hline & & & $\begin{array}{c}\text { nine funds, loans or } \\
\text { equity }\end{array}$ \\
\hline & & & $\begin{array}{l}\text { investments which focus } \\
\text { mainly }\end{array}$ \\
\hline & & & on South Africa43 \\
\hline FK Norway & 2004-2009 & 8.1 & $\begin{array}{c}\text { Six South African } \\
\text { exchanges }\end{array}$ \\
\hline
\end{tabular}

Source: http://www.unctad.org/sections/dite_dir/docs/wir03_fs.za.en.pdf

NORFUND's mandate is "to establish viable, profitable business activities which would not otherwise be initiated because of high risk". (Devfin Advisors, 2010a)(pg. 46) The role it plays is to be additional to the market by bridging the gap between state development aid and commercial investments. In simple terms, it is to take on risk where PSD would not, but where there is commercially viable business opportunities that are too risky for the market alone to take on. NORFUND actively participates on Boards of fund invested for building capacity. Success in measured on participation and capacity building of boards and improving HSE of investee companies as well as profitability. Aureos Southern Africa Advisors Ltd manages two funds in South Africa, one of which oversees three investment companies in South Africa.

\section{Relevance, Impact, Effectiveness, Efficiency and Sustainability}

As shown in Table 10 from the case study, the key programs implemented by Norway in South Africa have met with reasonable success as of 2010. NORFUND in particular has been scored very well and Application's based support shows need for further examination. As depicted in Table 10, two low scores would seem to correlate with each other.

Table 10. Summary assessment of the PSD programmes and projects in South Africa

\begin{tabular}{lccccccc} 
& $\begin{array}{c}\text { Match } \\
\text { making }\end{array}$ & $\begin{array}{c}\text { Application } \\
\text { based } \\
\text { support }\end{array}$ & $\begin{array}{c}\text { Norad soft } \\
\text { loans }\end{array}$ & $\begin{array}{c}\text { NHO } \\
\text { support } \\
\text { Agri SA }\end{array}$ & Norfund FK Norway \\
\hline Relevance & 3 & 3 & 3 & 3 & 3 & 2 \\
\hline Additionality & 4 & 4 & 3 & 4 & 3 & 4 \\
\hline Effectiveness & 4 & 2 & 4 & 4 & 4 & 3 \\
\hline $\begin{array}{l}\text { Sustainability } \\
\text { Institutional }\end{array}$ & 2 & 2 & 5 & 4 & 5 & 3 \\
efficiency & 4 & 2 & 3 & 4 & 5 & 4 \\
\hline $\begin{array}{l}\text { Cost- } \\
\text { effectiveness }\end{array}$ & 2 & 3 & 4 & 5 & 5 & 2
\end{tabular}

(Source: Devfin Advisors, 2010b)(pg. 64)

\section{Constraints (PSD)}

The annual report of the Accelerated and Shared Growth Initiative identified six main binding constraints for growth in South Africa:

1. Government capacity deficiencies

2. Currency volatility

3. Low levels of investment infrastructure and services

4. Skill shortages due to unequal education opportunities for black South Africans

5. Industrial and service sectors lack competitiveness

6. Inequality and marginalisation of ethnic groups

A separate effort by Country Partnership for South Africa identified the following constraints the same year:

1. Barriers to entry for small and medium-scale enterprises

2. Exchange rate volatility

3. Risk

4. Labour regulations

5. HIV/AIDS 
6. Lack of Greenfield investment by foreign firms due to crime, labour costs, and perceptions

A Common underlying theme is poverty, inequality and unemployment which are perceived as remaining characteristics left over from apartheid and which contributes to what is referred to as the "first" and "second" economies.

\section{Opportunities}

One opportunity is a program that is of particular interesting is NORAD financed Matchmaking Program (MMP), the purpose of which is to find matches between Norwegian and South African companies which could potentially become partners. As of 2010, the program is operated under contract with Innovation Norway which is based in Johannesburg with representation in Cape Town and Durban. Profiles are created for Norwegian companies looking for South African partners as well as other services such as market analysis. The overall objective of the program is to promote commercial activities between South Africa and Norway which eliminate poverty. Specifically, the $M M P$ is to this by "establishing sustainable and profitable partnerships between Norwegian companies and (local) companies which foster transfer of technology and the exchange of management and business-skills between the companies".(Devfin Advisors, 2010b)(pg. 25)

In the South Africa case study, the assessment of MMP performance is relatively low based on the key criteria of sustained commercial relations, transfer of know-how and technology, and employment generation and improved income. The cost effectiveness of the program has changed over the period of time from 1997 through 2009 in that, while the cost per match has decreased by $50 \%$, the cost per profile has doubled. Essentially, the cost has been shifted toward the front end of the process of match making with better screening during the profiling stage. The end result is that companies that enter into partnership searches are more likely to find successful paths forward toward sustainable business ventures which support the efforts that fit NORFUND's objectives.

The MMP program however failed to address at a policy level, both Norway's and South Africa's objectives of increasing the engagement with Black South Africans (Black Economic Empowerment). This presents itself as the greatest opportunity for Norway, through NORFUND, to further one of its primary objectives of decreasing poverty. The focus of the MMP has been on providing support to companies in general as compared to Black South African owned companies. (Devfin Advisors, 2010b)(pg. 31)

\section{Sri Lanka}

\section{Economic Conditions}

Historically, Sri Lanka had been perceived as an excellent example of internally driven human development compared to the country's economic development. This collapsed over time due to the near 30 year long civil war. In spite of this, Sri Lanka has maintained a surprising 5\% to $7 \%$ growth of its economy. Sri Lanka is considered a Lower Middle Income Country as of 2010. What is lacking is equality. Sri Lanka is considered to be comparable to countries in Latin America in terms of equality with economic stratification along ethnic lines.

Sri Lanka is unique from the perspective that Norway was directly involved in the conflict resolution efforts at the same time that it was conducting DFI efforts (Advisors, 2009). Norway's has development assistance has been much larger than its FDI in the 2000's. Sri Lanka then is in a situation where the aid it receives is much greater than the private capitol moving between Norway and Sri Lanka in the form if trade. This alone makes Sri Lanka unique in that it is receiving aid at a rate that Norway usually applies to Least Developed (LDC) countries. (Devfin Advisors, 2009)

\section{Investment Environment}

A major shift from a primarily agricultural based economy to a service based economy has taken place since the 1970's. Services are now $60 \%$ of the GDP and agriculture has diminished to only about $15 \%$. Ongoing ethnic unrest has made FDI challenging. As of 2009, little improvement in the overall environment had been made, however, maintaining status quo may well have been an accomplishment worth noting.

\begin{tabular}{|c|c|c|}
\hline Criteria & $\begin{array}{c}\text { Sri Lanka } \\
\text { rank 2009 }\end{array}$ & Trend 2005-2009 \\
\hline Doing business Overall & 102 & Slight improvement \\
\hline Starting of a business & 29 & Much improvement \\
\hline $\begin{array}{c}\text { Dealing with construction } \\
\text { permits }\end{array}$ & 161 & Some improvement \\
\hline Employing workers & 110 & No change \\
\hline Registration of property & 141 & No change \\
\hline Getting credit & 68 & Much improvement \\
\hline Protecting investors & 70 & No change \\
\hline Paying taxes & 164 & Negative trend \\
\hline Trading across borders & 66 & $\begin{array}{c}\text { Varying trends for different } \\
\text { sub-criteria }\end{array}$ \\
\hline Enforcing contracts & 135 & No change \\
\hline Closing a business & 43 & Slight decline \\
\hline
\end{tabular}

World Bank and IFC: Doing Business 2009, (www.doingbusiness.org) (Source: Devfin Advisors, 2009)(pg. 11)

\section{Norwegian Development Cooperation}

Norway has prioritized Sri Lanka as one of its top priorities for development since the late 1990s.This has however been perceived as an exercise in self-interest by some political factions in Sri Lanka. Norway's role as mediator between LTTE and the government has clearly made development investment a more complex endeavor. Trade between Norway and Sri Lanka has been and continues to be a very small portion of the trade volume of either country. 


\section{Ease of Doing Business}

An indicator of the attractiveness to business investment is that the volume of Foreign Direct Investment(FDI) has more than quadrupled between the early 2000's and 2008 when FDI was $\$ 900$ million and was expected to reach $\$ 4$ billion by 2012 .

Sri Lanka is rated as moderate in terms of Ease of Doing Business as measured by the World Bank and IFC. Competitiveness is moderate but improving, enhanced by microeconomic strengths, but hampered by macroeconomic weaknesses such as government debt.

\begin{tabular}{|c|c|c|}
\multicolumn{2}{|c}{ Doing Business in Sri Lanka } \\
\hline Criteria & $\begin{array}{c}\text { Sri Lanka } \\
\text { rank 2009 }\end{array}$ & Trend 2005-2009 \\
\hline Doing business Overall & 102 & Slight improvement \\
\hline Starting of a business & 29 & Much improvement \\
\hline $\begin{array}{c}\text { Dealing with construction } \\
\text { permits }\end{array}$ & 161 & Some improvement \\
\hline Employing workers & 110 & No change \\
\hline Registration of property & 141 & No change \\
\hline Getting credit & 68 & Much improvement \\
\hline Protecting investors & 70 & No change \\
\hline Paying taxes & 164 & Negative trend \\
\hline Trading across borders & 66 & Varying trends for different \\
sub-criteria
\end{tabular}

(Source: Devfin Advisors, 2009)(pg. 11)

Relevance, Impact, Effectiveness, Efficiency and Sustainability

Summary assessment of the PSD programs and projects in Sri Lanka

\begin{tabular}{|c|c|c|c|c|c|c|c|}
\hline \multicolumn{2}{|c|}{ Match making } & $\begin{array}{c}\text { Application } \\
\text { based } \\
\text { support }\end{array}$ & $\begin{array}{c}\text { Norad } \\
\text { loans }\end{array}$ & $\begin{array}{c}\text { Embassy } \\
\text { support } \\
\text { HDCC }\end{array}$ & SF & NORFUND & $\begin{array}{c}\text { FK } \\
\text { Norway }\end{array}$ \\
\hline Relevance & 3,5 & 3,5 & 3 & 1 & 3 & 3 & 1,5 \\
\hline Additionality & 4 & 3 & 4 & 5 & 2 & 3 & 3 \\
\hline Effectiveness & 5 & 3 & 3 & 1 & 2 & 3 & 3 \\
\hline Sustainability & 3 & 3 & 3 & 1 & 3 & 5 & 3 \\
\hline $\begin{array}{c}\text { Institutional } \\
\text { efficiency }\end{array}$ & 3,5 & 3 & 2,5 & 1,5 & 2,5 & 3 & 3 \\
\hline $\begin{array}{c}\text { Cost- } \\
\text { effectiveness }\end{array}$ & 3 & 3 & 4 & 1 & 2 & 5 & 2 \\
\hline
\end{tabular}

(Source: Devfin Advisors, 2009)(pg. 77)

\section{Constraints}

Sri Lanka has a number of issues which hamper Private Sector Development as identified in the case study. These include a rigid labor market, ethnic unrest, high taxation, excessive bureaucracy with regard to property registration and other forms of permissions, high inflation and government debt, limited inflow of foreign investment and conservative credit requirements for small and medium businesses.
There is some sign of slow improvement in credit to small and medium businesses. Also, Sri Lanka is a socialist welfare state for which the war has added a heavy tax burden. The war is seen to have lasting but somewhat diminishing underlying impacts on growth and the constraints on growth.

Assessing Norwegian PSD against 'binding constraints'

\begin{tabular}{|c|c|}
\hline Binding constraint & Portfolio assessment \\
\hline The ethnic war & $\begin{array}{l}\text { Overall strong effort by Norwegian government } \\
\text { to resolve conflict. PSD support not aligned with } \\
\text { these efforts }\end{array}$ \\
\hline Rigid labour market & Not addressed \\
\hline High degree of taxation & Not addressed \\
\hline $\begin{array}{c}\text { Bureaucratic legal system } \\
\text { Weak macroeconomic } \\
\text { management }\end{array}$ & $\begin{array}{c}\text { Not addressed except for limited input in IFC } \\
\text { project financed by Embassy }\end{array}$ \\
\hline Limited inflow of FDI & Major thrust of the PSD support \\
\hline Credit for SMEs & $\begin{array}{c}\text { Partly addressed by Embassy IFC projects, and } \\
\text { microfinance }\end{array}$ \\
\hline
\end{tabular}

(Source: Devfin Advisors, 2009)(pg. 77)

\section{Opportunities}

Sri Lanka represents a long and well established active economic development and political relationship with Norway. Because of this, Norway has established some trust equity in the country. That trust provides opportunity for NORAD/NORFUND to begin to scale up those programs which have had the most impact. To do so however will require some reflection on the impact and outcomes that have thus far been achieved. As of 2010, the number of jobs, for instance, added to the economy is miniscule. Herein lies a key opportunity for DFI targeted efforts.

Measurement of program effectiveness and impact in a quantitative sense would clearly enhance the overall design of development strategies for further DFI efforts in Sri Lanka. Fragmentation of development efforts might very well be decreased by establishing a standard set of measurements for each project taken on when the size and scope of the project make it valuable to do so.

Political stability is likely to continue to be a key factor in development possibilities in Sri Lanka.

\section{Uganda}

\section{Economic Conditions}

Uganda's economy is one of the fastest growing in the world as of 2010. However, population growth provides for a high dependency rate and will demand that the economic growth continue.

Poverty has declined measurably but income inequality is substantial between the South-West and North-East. Health indicators have improved, HIV/AIDS has been reduced, and both infant and maternal mortality rates have decreased. Additionally, a signed agreement creating a common market for East Africa has created some possible 
opportunities in that movement of goods, services and labour is now freer. Also customs duties have been reduced.

In spite of these economic positives, the political situation is dynamic, with civil war in the North and a willingness to exploit Eastern Democratic Republic of Congo. As of 2010 the donor community is critical of the government's role in governance and democracy. (Devfin Advisors, Evaluation of Business-related Assistance: Uganda Case Study, 2010)

\section{Investment Environment}

Uganda, much like Sri Lanka is agriculture intensive. Horticulture and floriculture have seen increased roles recently along with tourism. The move toward manufacturing has been slow partly due to being land-locked. The Small and Medium Enterprise sector has, however shown strength. This has been helped by investment in the communications sector with exceptional growth of cell phone usage. Access to fiber-optic technology by private investors along the East coast of Africa was expected to further increase the stability of the system as of 2009 .

Both capital markets and Foreign Direct Investment have found success in Uganda. The financial crisis did not have much effect due financial institutions in Uganda not being heavily exposed to international markets.

\section{Norwegian Development Cooperation}

Norway began a development relationship with Uganda with a five year Memorandum of Understanding ten years after the President Museveni came to power in 1986, though direct bilateral aid was provided during that previous ten year period. A subsequent fiver year Memorandum of Understanding was established which formally carried the relationship through 2005. The initial understanding stressed 1) Good Governance; 2) Economic Growth and PSD; 3) Social Development. Cross cutting issues related to natural resources, education and health were also addressed. The latter MoU was reviewed in 2004 without further action being taken due to reluctance of some ministries in the Ugandan Government.

As of 2010 Norway had very little trade with Uganda with only about ten million USD worth each of imports and exports taking place in the four years between 2005 and 2009. Only one recorded investment had taken place as of 2007.

\begin{tabular}{|c|c|c|c|c|c|c|}
\hline \multicolumn{2}{|c|}{2005} & 2006 & 2007 & 2008 & $\begin{array}{c}2009 \\
\text { (Jan -Oct) }\end{array}$ & $\begin{array}{c}\text { Total 2005- } \\
2009\end{array}$ \\
\hline Exports & 1,2 & 0,6 & 2,6 & 2,5 & 3,0 & 9,6 \\
\hline Imports & 2,4 & 2,1 & 1,8 & 2,2 & 1,3 & 9,7 \\
\hline Thereof GSP & n/a. & 1,5 & 1,2 & 1,9 & n/a. & n/a. \\
\hline
\end{tabular}

Source: Table 3 from Uganda Case Study (Section 3.2)

It is clear that cooperation between Norway and Uganda has been very limited since engagement began.

\section{Ease of Doing Business}

Uganda is rated as moderate as far as the regulatory framework for doing business. Based on the World Bank and IFC's 2010 Doing Business Report. Recent Improvement has been noted but I marginal as shown in table\#.

\begin{tabular}{|c|c|c|}
\multicolumn{4}{|c}{ Doing Business in Uganda } \\
\hline Criteria & Rank 2010 & Trend 2007-2010 \\
\hline Doing business overall & 112 & Slight improvement \\
\hline Starting of a business & 129 & No change \\
\hline Dealing with construction & 84 & Some improvement \\
\hline Employing workers & 7 & Slight improvement \\
\hline Registration of property & 149 & No change \\
\hline Getting credit & 113 & No change \\
\hline Protecting investors & 132 & No change \\
\hline Paying taxes & 66 & Some improvement \\
\hline Trading across borders & 145 & $\begin{array}{c}\text { Varying trends for different } \\
\text { sub-criteria }\end{array}$ \\
\hline Enforcing contracts & 116 & Slight improvement \\
\hline Closing a business & 53 & No change \\
\hline
\end{tabular}

(Source: Devfin Advisors, 2010a)(pg. 18)

Competitiveness in Uganda is hampered by a perception of weakness in the area of access to financing. Corruption is also hindering business growth and the greatest perceived area of corruption in Uganda is in the judiciary followed by public officials and public servants. The business sector is not seen as particularly corrupt.

\section{Relevance, Impact, Effectiveness, Efficiency and Sustainability}

As is clearly shown in the following table, both the micro-finance cluster and one of the NORFUND programs have rated very well in Uganda across all measured parameters.

Summary assessment of PSD programmes and projects in Uganda

\begin{tabular}{|c|c|c|c|c|c|c|}
\hline \multicolumn{2}{|c|}{$\begin{array}{c}\text { NHO Norad projects in } \\
\text { loans production* (Jambo) }\end{array}$} & $\begin{array}{c}\text { Embassy } \\
\text { support } \\
\text { UNIDO }\end{array}$ & $\begin{array}{c}\text { Micro- } \\
\text { finance } \\
\text { cluster }\end{array}$ & NORFUND** & $\begin{array}{c}\text { FK } \\
\text { Norway }\end{array}$ \\
\hline Relevance & 2,5 & 2 & 3 & 5 & $2-5$ & 2 \\
\hline Additionality & 4 & 3 & 4 & 4 & $3-5$ & 3 \\
\hline Effectiveness & 2 & 2 & 3 & 4 & $1-4$ & 3 \\
\hline Sustainability & 2,5 & 2 & 1,5 & 5 & $1-4$ & 3 \\
\hline $\begin{array}{c}\text { Institutional } \\
\text { efficiency }\end{array}$ & 2,5 & 2 & 3 & 4 & $1-4$ & 3 \\
\hline $\begin{array}{c}\text { Cost- } \\
\text { effectiveness }\end{array}$ & 2,5 & 1 & 3 & 2 & $1-4$ & 2 \\
\hline
\end{tabular}

* Includes ABS support to projects facilitated by NHO and Norad loan borrower, respectively

** The higher figure refers to NORFUND's investments in Aureos/UML/BRAC Africa/regional funds, the lower to DFCU/ Abacus (Source: Devfin Advisors, 2010a)(pg. 88))

\section{Constraints}

The World Bank concluded in the most recent country economic memorandum (as of the writing of the case study) that the growth strategy of Uganda is working well, but the growth path is limiting. There is a 'demographic time bomb' 
which must be faced in that the fast expanding work force will need to transition from farm to urban employment. Infrastructure to support export focused economy will require more PSD as well as FDI. Additionally, banks will need to provide credit more readily than has been the norm.

Poor infrastructure needs to be addressed in order to reduce indirect costs. Of the infrastructure sectors, energy is the most constraining. Transportation is the next most important constraint with regard to infrastructure. Poor rail and road services on top of a poor rail compound the problem, leading to high international transport costs.

\section{Opportunities}

One key opportunity in Uganda which exists in spite of NORAD/NORFUND efforts already made is in the area of "The Missing Middle". The missing middle represents an area of financial investment in projects which lie between micro-finance and commercial bank interests. The volume of micro-finance loans as well as the reported success of such loans implies that there are numerous opportunities to grow small successful businesses into larger medium sized businesses if loans of an intermediate size were available. Those medium sized businesses are likely to employ more people as well as further contribute revenue for the building and maintaining of infrastructure projects which business relies on.

There is a rather glaring opportunity in that the coordination of efforts between various Norwegian investment organizations is in some cases utterly lacking. Such fragmentation leads to lost opportunities and is detrimental to both Uganda and the institutions Norway relies upon to carry out their development investment goals.

It would seem that Uganda is another example of a country where the Match Making Program would benefit the efforts of Norwegian bilateral development investment interests. As noted, there is a miss-match of technical business capabilities between Uganda and Norway. There is good reason that this could begin to be addressed by strategic exchanges similar to those undertaken in South Africa, and that such an effort may enhance the possibility of further success in current and future development projects.

\section{Summary and Conclusions}

A stark contrast in the nature of binding constraints is shown between the three countries and depicted in each case study. While the most obvious for Sri Lanka is the long standing ethnic war, the rest are largely structural: high taxes, poor access to credit, inflation and labour market are identified. This is in contrast to Uganda where corruption, energy and transportation along with institutional deficiencies are the key components which constrain growth. Furthermore, South Africa is observed to be burdened by a much broader range of issues, many of which are leftovers from apartheid. Government capacity along with weak and uncompetitive industrial sector is noted, but many of the constraints surround social issues such as marginalization and lack of access to education. Also key in the South Africa are broad financial issues such as a volatile currency and "low levels of investment infrastructure and infrastructure services" (pg 14, South Africa case study).

The NORAD/NORFUND combination have made clear efforts to monitor, evaluate and report on efforts made in the three countries for which case studies were examined for this paper. That being said, it is clear that further design work on standardized measurements for projects undertaken by Norway would be beneficial. There are numerous instances where program success or failure may have been identified earlier in a project, or in some cases, failure prevented had there been solid quantitative and qualitative measurements in place for operational monitoring and ongoing project reporting.

Each of the following is actions suggested by this research which would lend themselves well to enhancing NORFUND efforts, and DFI efforts in general. All but two of these recommendations are related in some way to the establishment of good measurement techniques.

- $\quad$ NORFUND needs to develop consistent measurements and reporting standards which will indicate success against NORFUND's goals of reducing poverty. Specifically, counterfactuals need to be employed in analysis of program outcomes/impacts. At the same time, continued reporting on efficiency needs to be maintained. Incorporating both will be difficult but worthwhile.

- FK (exchange program) program needs to be developed so that it is cost effective so the program can be expanded. Sri Lanka is a good example of where the FK program could enhance the initialization of sustainable business by ensuring business skills are available in the target country and sector.

- Financial and legal competence of the investment staff at NORFUND needs to be constantly monitored to ensure that the skills and knowledge of staff are able to navigate the complexities of each countries legal framework.

- Investment staff should be trained to ensure that investee companies are in compliance with the Environmental, Social and Governance (ESG) goals and to re-enforce ESG as a top priority.

- NORFUND should consider developing more integrated and standardized financial risk management practices. NORFUND should also improve coordination in its due diligence (DD) and risk management process.

- The Match Making Program (MMP) is important in that it does the groundwork as a service to private sector development. This would be prohibitively expensive for most companies. The MMP should focus more effort on up front profiling of both investor and investee companies in order to maximize the probability of successful long term partnerships. 


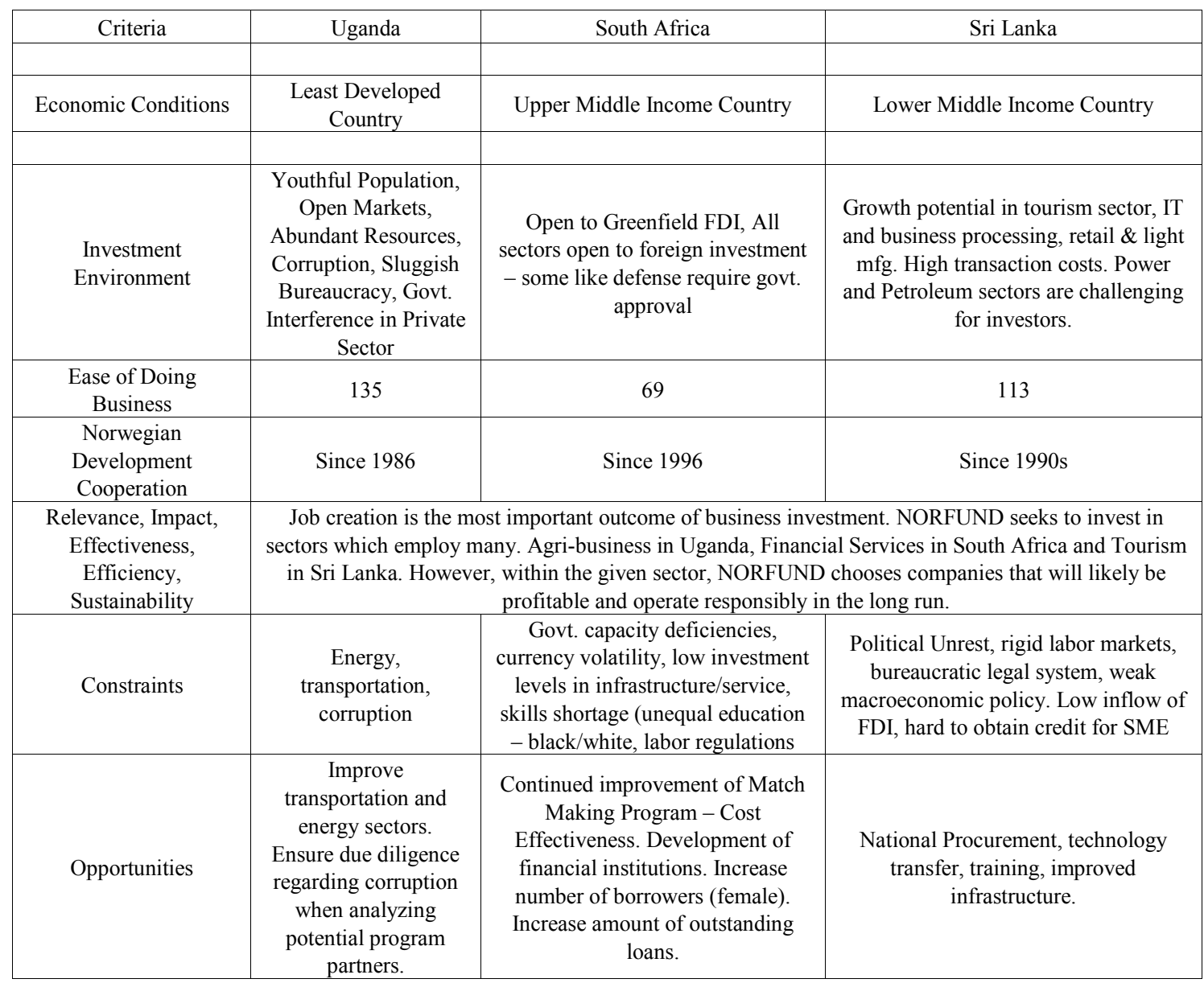

\section{Consistent Measurement of Outcomes}

The primary area of opportunity is in measurement of impacts. The details in the case studies offer some indications that jobs have, in some cases, been created through bilateral and multilateral efforts in the private sector as well as in the public sector. However, the data is not quantifiable at the level of the economic system where impact can be measured or compared to areas where such efforts have not been made. Part of the problem is that the goals of NORFUND are very broad: Reduce poverty, further engage women in businesses, and engage in sustainable best practices. At the same time, these goals are difficult and seem at odds with NORFUNDs measurement techniques. NORFUNDs limited size does play into the impact.

\section{Investing Arena}

NORFUND simply does not take into account the impact that their investments make. What they do take into account are outputs and outputs. NORFUND puts a priority on obtaining reliable information regarding their investments while avoiding unjustifiable reporting burdens on involved parties. The justification for this is that NORFUND invests in very challenging markets, where a balance needs to be struck between reporting requirements and administrative burdens. NORFUND sees itself as a small actor, where projects outcomes and outputs are measureable, whereas impact is not. Additionally, NORFUND prefers annual ex post results from entire portfolios based on a small number of indicators targeting strategic achievement and project results that are relevant and easy to obtain. (NORFUND)

The nature of the challenges that DFIs take on, encompass in their role of financing, higher-risk programs and projects which require that both quantitative and qualitative measurements of outcomes be designed into all levels of a DFIs operations. Based on the research in this paper, there is a need to re-examine measurements of success or failure in order to maximize the outcomes of DFI efforts. In particular, while avoiding burdensome requirements on recipients is important, the question needs to be asked: Is the data that is collected sufficient to determine whether NORFUND is achieving its broader mission goals which are impact related?

DFIs generate and support numerous kinds of program which target the goals of their charter, or mission. There is a clear advantage in designing impact measurements which identify success for each program as well as the projects which that program funds or otherwise supports. The key to the design of such measurements is that the design be an 
integral part of the program and project design. The question of 'how do we measure success?' must be asked throughout the program design, and subsequently after the project has been completed.

Case studies such as those reviewed during this research show that DFIs such as NORFUND do have measurement requirements at a policy level, and to some extent, at the micro economic level, that attempt to address the broader goals of NORFUND. However, these seem to be implemented as an afterthought, or in review only after much effort has been invested in a given program or project. Establishing quantitative and qualitative measurements during program and project design at the beginning of the process would provide better data for analysis in determining and successful outputs outcomes as well as impact.

As described in all three case studies, there are often numerous and complex regulations, and regulating bodies with which DFIs must work with. Expertise in the business framework of developing countries requires a great deal of attention. There are three major challenges faced: Reluctant or ineffective regulatory bodies, regulatory bodies which are in the process of rapid change, and political influence applied through regulatory bodies. In order to maximize project success, In-house expertise regarding these challenges is arguably a part of due diligence. The FK program may be a very good way to develop such in-house expertise.

The Match Making Program (MMP) is intriguing in that the intent of the program, if carried out effectively, enables companies from both the investor and investee countries to find partners which are suitable matches. This could very well be the 'hidden gem' of the programs which NORFUND has invested. The up-front data gathering and analysis of companies can be prohibitively resource consuming and expensive. NORFUND offering this service effectively provides a substantial head start for companies who are looking for partners. This program has excellent potential for better enabling not only the companies which may partner, but for identifying opportunities for DFI and private sector investors.

\section{REFERENCES}

[1] Advisors, D. (2009). Evaluation of Norwigian Business-related Assistance: Sri Lanka Case Study. Oslo, Norway. Retrieved fromhttps://www.norad.no/en/front/abou t-norad

[2] Devfin Advisors. (2009). Evaluation of Norwegian Business-ralated Assistance: Sri Lanka Case Study. Oslo, Norway. Retrieved fromhttps://www.norad.no/en/front/abou t-norad/

[3] Devfin Advisors. (2010). Evaluation of Business-related Assistance: Uganda Case Study. Oslo, Norway. Retrieved from https://www.norad.no/en/front/about-norad

[4] Devfin Advisors. (2010). Evaluation of Norwgian Business-related assistance: Sourth Africa case stuy. Oslo, Norway. Retrieved fromhttps://www.norad.no/en/front/abou t-norad/

[5] Jouanjean, M.-A., \& te Velde, D. W. (2013). The role of development finance institutions in promoting jobs and structural transformation: a quantitative assessment. ODI Working Papers. ODI.

[6] Khandker, S. R., Koolwal, G. B., \& Samad, H. A. (2010). Handbook on Impact Evaluation: Quantitative Methods and Practices. Washington D.C.: World Bank. doi:10.1596/978-0 $-8213-8028-4$

[7] Lydenberg. (2014). Emerging trends in environmental, social, and governance data and disclosure: opportunities and challenges. (32). Retrieved from http://documents.worldbank .org/curated/en/2014/01/19604851/emerging-trends-environ mental-social-governance-data-disclosure-opportunities-chal lenges

[8] Musasike, L., Stilwell, T., Makhura, M., Jackson, B., \& Kirsten, M. (2004). The role of Development Finance Institutions: Lessons from southern Africa of best practices for. 6th Annual Financial Markets and Development Conference. Washington, DC: World Bank. Retrieved from http://www.worldbank.org/wbi/banking/finsecpolicy/stateow ned2004/

[9] Schmidt, R. H., \& Winkler, A. (2011). Bilateral development finance institutions in Europe: A comparative analysis of DEG, CDC, FMO and Norfund with recommendations for development policy. Austrian Foundation for Development Research(OFSE). 